\title{
Numerical Evaluation of the Tensional-Deformational State of the Blade in the Gamesa G52/850 Wind Turbine During the Action of Extreme Wind
}

\author{
${ }^{1}$ Pedro Limas, ${ }^{1}$ Carlos Trinchet, ${ }^{1}$ Pavel Almaguer, ${ }^{2}$ Javier Vargas and ${ }^{3}$ Lauren Isaza \\ ${ }^{1}$ University of Holguin, Holguin, Cuba \\ ${ }^{2}$ Research Group GIPIS, Universidad Cooperativa de Colombia, Villavicencio, Colombia \\ ${ }^{3}$ Research Group GITSAI, Minuto de Dios University Corporation-Uniminuto, Villavicencio, Colombia
}

\begin{abstract}
In this research is exposed to procedure to determine the mechanical behavior of the blade during extreme wind action for the GAMESA G52/850 wind turbines installed in the Gibara Wind Farm. For this, the complex geometry of esta blade is analyzed and its $\mathrm{CAD}$ modeling is performed, the sequence is defined to determine the loads acting, making the evaluation of the tensional-deformational state before different positions of the blade with respect to the mast. The finite element method analyzes the convergence of the mesh without detecting significant differences. The results of the numerical simulation showed that in front of winds of 250 $\mathrm{km} / \mathrm{h}$ in a position of $90^{\circ}$ (Flag) the blade resists the stresses to which it is subjected, however, it is not so in the $0^{\circ}$ position. For winds greater than $250 \mathrm{~km} / \mathrm{h}$ in any of the cases. These loads are supported. Considering the enormous dimensions of this type of wind turbine and that in the face of adverse weather conditions there is no possibility of collapsing or disarming it has-been scientifically demonstrated that the (Flag) position is the available option to reduce damages.
\end{abstract}

Key words: Wind turbine, wind speed, blade, fluid, simulation, scientifically demonstrated

\section{INTRODUCTION}

The care for nature and its ecological environment is an urgent task for humanity, ruthless and irrational use of natural resources can lead to extinction of natural habitat.

Denmark is one of the great countries worldwide leader in the development of wind turbines (Muljadi et al., 2007). This rapid development of wind power industry has allowed companies such as Goldwind, GAMESA, SIEMENS, VESTA ENERCON, among others invest millions of dollars with state subsidies that encourage the installation of huge fields and wind turbines.

In Cuba, there to obtain electricity wind farms with horizontal type machines above $200 \mathrm{~kW}$, connected to the national grid (Avila-Prats et al., 2010). Others are in development, mainly in the province of Holguin.

Cyclones in the Cuban archipelago are frequent and diverse for its route and intensity. Nothing must be projected in relation to the use of wind energy without a systemic and historical forecast that reality.

In the wind farm Gibara twelve generators are housed, six of the Spanish firm Gamesa G52/850 and other manufacturing China Goldwind S50/750, although, it has the technology for proper operation, there is information and references related to the behavior of the blades of these wind generators different ranges of wind speed with respect to the stresses, strains and displacements; primarily to the passage of tropical hurricanes nor is it has numerical simulation of the blades relative to the rate of extreme wind before this a problematic based on escaza measures taken to put the blades in position "Flag" is formulated before the possibility of extreme winds.

\section{MATERIALS AND METHODS}

Mechanical behavior of wind turbine blades, at ranges extreme wind speed: Wind turbines are distinguished over conventional machines in that its operation besides depending on the technical state is conditioned by this wind resource, i.e., a range of wind speed which ensures its stable work. This imposes the need to study the interrelationship wind turbine with a systemic and integrating perspective ( $\mathrm{Li}$ and Chen, 2008).

The blades of a wind turbine are similar to the wings of an airplane model. In fact, designers used shovels classic profiles of wings and propellers aviation as a cross section of the outermost part of the blade. The function of the blade is capturing the wind kinetic energy into mechanical energy and turn applied to the rotor axis by these is its airfoil, changes its angle and angular velocity (Fig. 1).

Corresponding Author: Pedro Limas, University of Holguin, Holguin, Cuba 


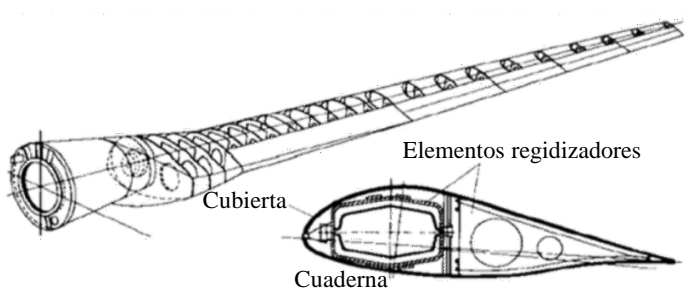

Fig. 1: Shovel modern structure (Funes Ruiz, 2009)

Used for prediction models associated wind speed wind power methods: Wind variations in the direction of the current flow are characterized by the Power Spectral Density (PSD) of the longitudinal component of the instantaneous speed. A series of functions of PSD are used as models in the field of wind energy data when power spectral density of turbulence are not available for a certain location (4).

The model of the power spectrum of Kaimal was adjusted based on experimental data collected neutral atmospheric conditions on a flat location in Kansas (USA) (Kaimal et al., 1972) (Eq. 1):

$$
\operatorname{PSD}_{\text {Kaimal }}(f)=\frac{105 . v_{*}^{2} \cdot z \sqrt{V}}{(1+33 f \cdot z \sqrt{V})^{5 / 3}}
$$

IEC 61400-1 international standard (Lassig et al., 2011) for the requirements in the design speci fi c wind turbines PSD type Kaimal (Preidikman and Mook, 2005) (Eq. 2):

$$
\operatorname{PSD}_{\mathrm{IEC}}(\mathrm{f})=\sigma_{\mathrm{v}}^{2} \cdot \frac{2 \cdot \frac{\mathrm{L} \eta}{\mathrm{V}}}{\left(1+6 \cdot f \cdot \frac{\mathrm{L \eta}}{\mathrm{V}}\right)^{5 / 3}}
$$

Where:

$\mathrm{V}=$ The average wind speed $(\mathrm{m} / \mathrm{sec})$

$\sigma_{v}^{2}=$ The standard deviation of the wind speed in a range of $10 \mathrm{~min}$

$L \eta=$ The integral length scale

given by:

$$
L_{1}= \begin{cases}5.67 \cdot z & z \leq 60 m \\ 340.2 m & z>60 m\end{cases}
$$

In any case in both forms of modeling wind farm (diversified model or aggregate model), from the point of view of power fluctuations, wind modeling is a very important factor.

A common way to treat the stochastic part of the wind is dividing the system into a model power spectral density and other spectral model spatial coherence. (a)

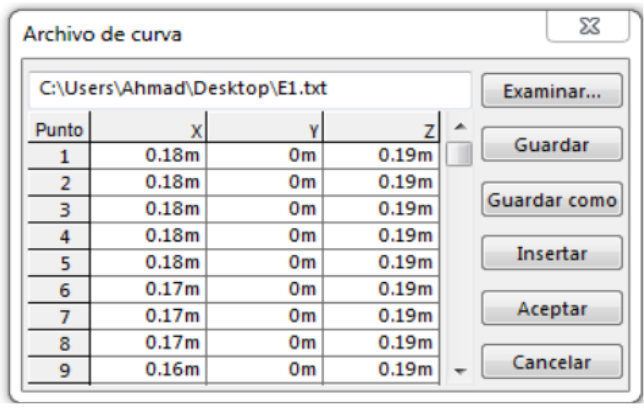

(b)

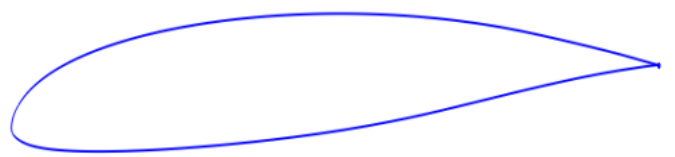

Fig. 2: a) Table of points in the $x-z$ and b) Profile modeling CAD system shovel

Table 1: Saffir-Simpson hurricane classification (Lizano, 2007)

\begin{tabular}{lcc} 
Category & Central pressure $(\mathrm{hPa})$ & Maximum sustained wind $(\mathrm{km} / \mathrm{h})$ \\
\hline 1 & 980 & $118-153$ \\
2 & $965-979$ & $154-177$ \\
3 & $945-964$ & $178-209$ \\
4 & $920-944$ & $210-250$ \\
5 & $<920$ & $>250$ \\
\hline
\end{tabular}

The Power Spectral Density (PSD) of the wind speed, represents the frequency distribution of energy in the fluctuating component of the wind andhas been shaped from the study of turbulence in the boundary layer air by von Karman. Subsequently, Kaimal developed a model (Kaimal et al., 1972) has been used frequently in the field of wind energy (Fernandez-Baqueiro et al., 2009).

\section{Analysis and modeling of wind turbine blade GAMESA G52/850}

Blade profile: The blade profile proposed in Fig. $2 \mathrm{~b}$ has a shape eliptica. Para generate the complex profile of the blade was necessary to prepare tables for points in the $x-z, F i g .2 a$, this yielded results close to reality as shown in Fig. 3. In the front view of the Fig. 3, the model of the wind turbine blade GAMESA G52/850 with raised above features can be seen.

Defining ranges extreme wind speed used in the study of the blade: The hurricane information is also used in the engineering design of the construction of the tower supporting the nacelle of the wind turbine whichmust withstand winds of hurricanes and sustained as well as the intrinsic characteristics of this type of winds (Table 1). 


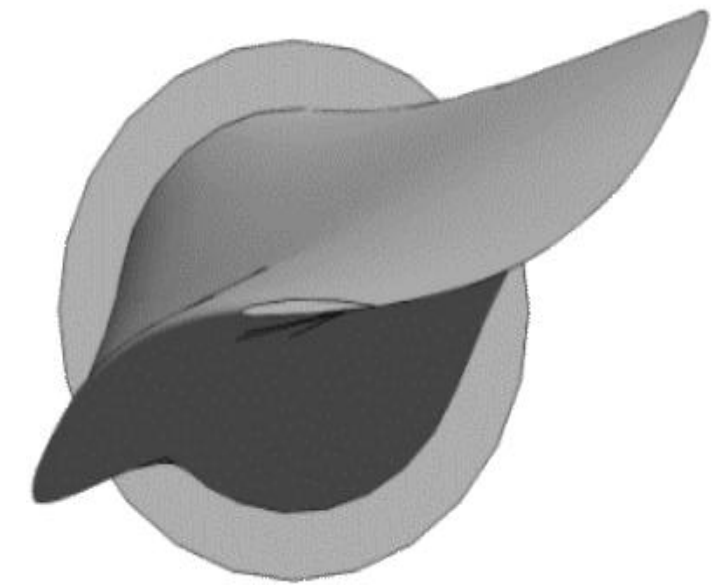

Fig. 3: Profile of the blade in front view developed in $\mathrm{CAD}$ system

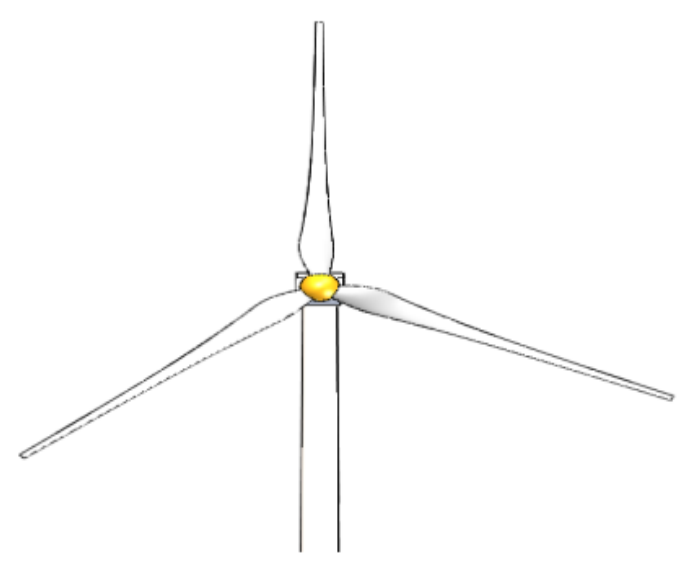

Fig. 4: $0^{\circ}$ with respect to the mast

Sequence for global objects of extreme wind force: Two different positions with respect to the mast angle to the blade, the first at $0^{\circ}$ with respect to the mast and the other at $90^{\circ}$ (position "Flag") were studied which is adopted to deal with natural phenomena upon the occurrence of strong winds that can cause damage to the structure (Fig. 4). This position "Flag" is used in aviation propeller engines when an engine stop in midair occurs to reduce aerodynamic drag.

\section{RESULTS AND DISCUSSION}

Results of the forces acting on the blade by the action of extreme wind: The simulation shows the flow behavior with respect to pressure and flow velocity of extreme wind on the blade to a position of the object concerned select the appropriate view in correspondence with the nature of the phenomenon to be modeled velocity profiles are then displayed and wind pressure acting on the blade where

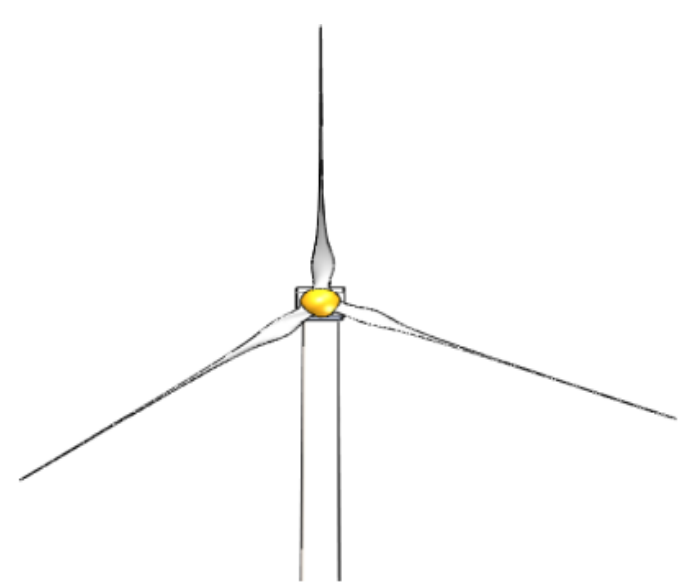

Fig. 5: $90^{\circ}$ with respect to the mast (position "Flag")

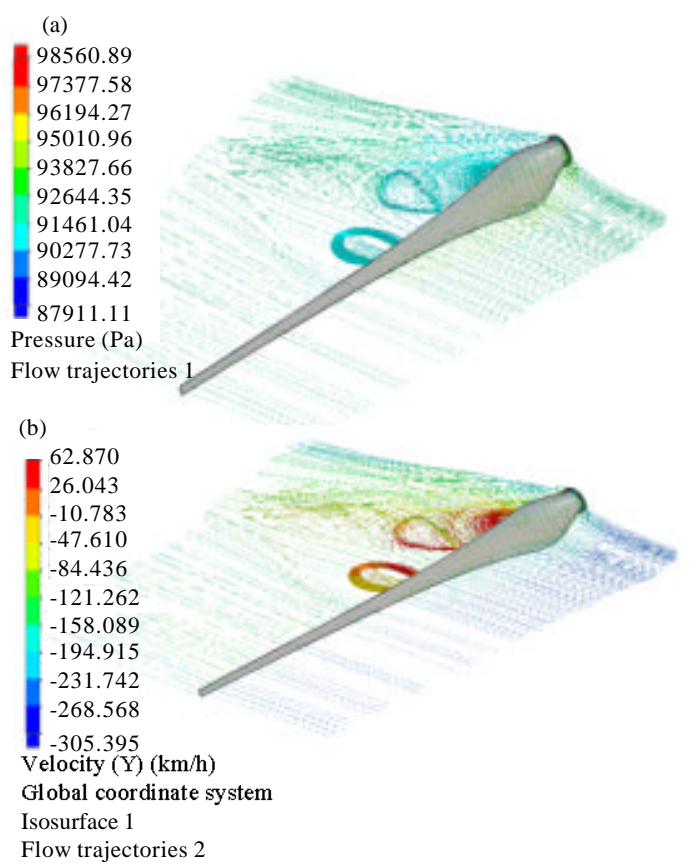

Fig. 6: a) Change of pressures that may result in category 5 hurricane in the wind turbine blade and b) Path maximum wind speed which may cause a category 5 hurricane on the wind turbine blade

turbulence and complex vortices occur (Fig. 5b) path maximum wind speed which may cause a category 5 hurricane on the wind turbine blade (Fig. 6a, b).

It is observed that there are areas of greater pressure on the front of the blade where your body is wider and vortices it increases tensions.

Determining the state of stress and deformation of the blade: The calculation methodology starts from the initial 


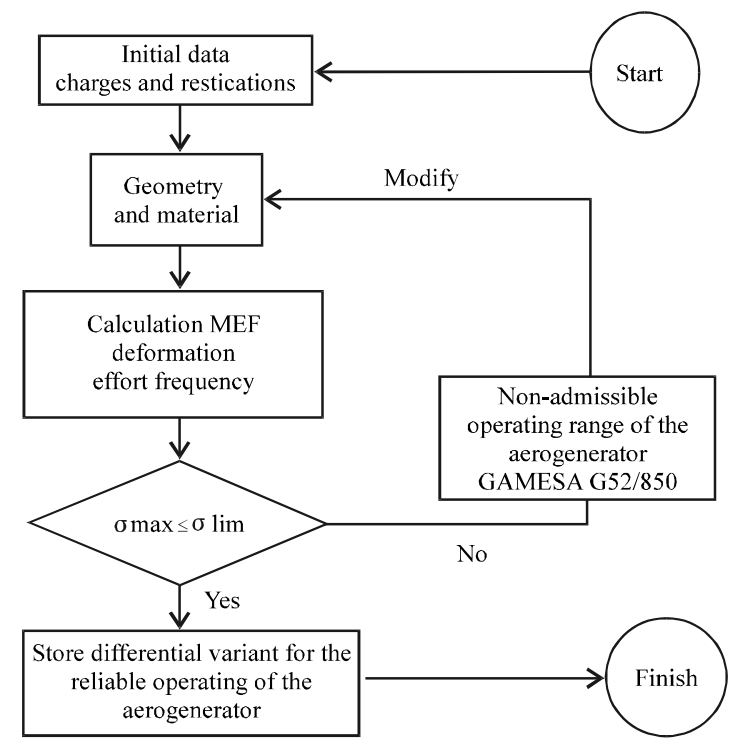

Fig. 7: Calculation scheme for the stresses and strains

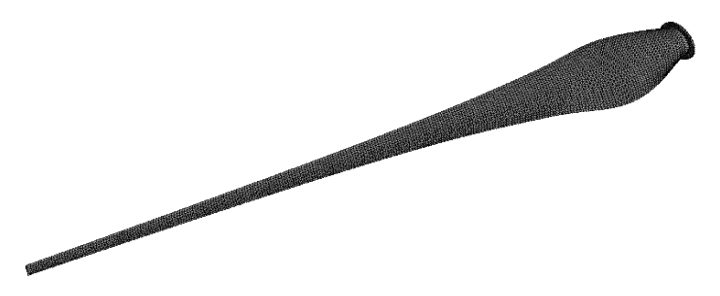

Fig. 8: Mesh type obtained by simulation

data of the blade; burdens and restrictions whichare associated with the geometry of the turbine GAMESA G52/850, subjecting it to a finite element analysis of stress, strain and frequency for determine the ranges not resist (Fig. 7).

Simulation of the blade to the loads obtained: The values of global objects such as force, friction force, pressure and speed, obtained with the simulation were exported as a mechanical load acting on the wind turbine blade GAMESA G52/850 because the constant flow behavior on the blade to a static load equivalent to the direction and wind direction (Bououden et al., 2013; Diaz et al., 2005; Gebhardt et al., 2008; Herrera-Sanchez et al., 2010; Limas Rodriguez et al., 2017; Limas Rodriguez, 2013; Lizano, 2007).

Meshing model: It is assumed that the constitutive material model is linear isotropic. The type of finite element is quadratic high order. The mesh has 59,962 elements and 98,380 nodes. The size of the elements is 80 $\mathrm{mm}$ while the tolerance is $4 \mathrm{~mm}$ (Fig. 8).
Procedure for determining the mechanical behavior of the blade during extreme wind action: Simulating the behavior of the stresses, strains and safety factor of the blade is made, under the influence of extreme wind for two positions. It is intended to show that if the blade is not placed in the "Flag" position when it is in extreme wind, tends to deterioration, deformation and even fatigue failure.

To position the blade angle of $0^{\circ}$ with respect to the mast and winds of $250 \mathrm{~km} / \mathrm{h}$ with a pressure of $92,000 \mathrm{~Pa}$, the stresses ( $\sigma$ ) static acting according to the von Mises criterion in the blade have a maximum value $169 \mathrm{MPa}$, the displacements are large with maximum value of $6.23 \mathrm{~m}$, corresponding to the safety coefficient (ne) and given the elastic limit of the material $(\sigma e)$ has a minimum value of 0.36 which can not withstand the stresses to which it is subjected (Fig. 9c). Distribution safety factor regarding the elastic limit of the material.

These values are considered dangerous for subjected to high loads during high winds action element which produce high peak values extreme loads and stresses associated by far exceeding the breaking limit of the material, cause deformations and cracks by sudden fractures and considerable damage to the structure itself. For an item like blade having a length of $52 \mathrm{~m}$ and works up to $2000 \mathrm{sec}^{-1}$ is a prerequisite to maintain the dynamic balance through its high aerodynamic qualities and symmetry.

Position of the blade 90 degrees with respect to the mast: To position the blade angle of $90^{\circ}$ with respect to the mast and winds of $250 \mathrm{~km} / \mathrm{h}$ with a pressure of $92,000 \mathrm{~Pa}$, the maximum values of stress ( $\sigma$ ) static acting according to the von Mises criterion in the blade reach $9.27 \mathrm{MPa}$, displacement $0957 \mathrm{~m}$, corresponding to the safety coefficient (ne) and given the elastic limit of the material (oe) has a minimum value of 2.2 , so, you resist the stresses to which it is subjected (Fig. 10).

Analysis of the results of the blade: To analyze the blade 10 under different criteria static studies were performed. These loads obtained for each speed value and extreme wind pressures applied, taking into account the tensions of cuts. The analyzes yielded determinants results for greater criterion reactions forces acting on the blade in the two working positions analyzed, $0^{\circ}$ with respect to the mast and $90^{\circ}$ with respect to the mast see (Table 2 and 3 ). 
(a)

von Mises (N/mm (MPa))

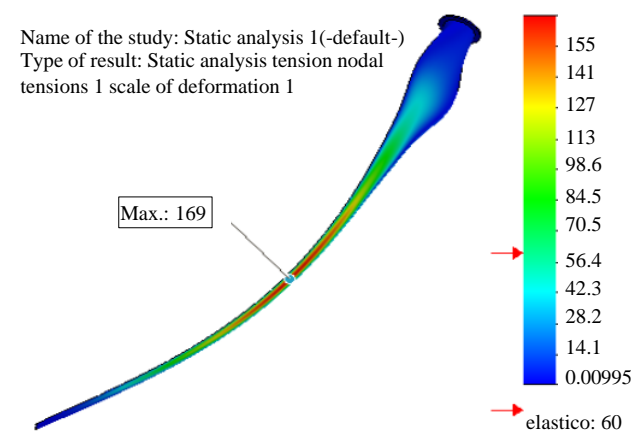

(c) (b)

ame of the study: Static analysis 1(-default-) Type of result: Static displacement displacement1 deformation scale: 1

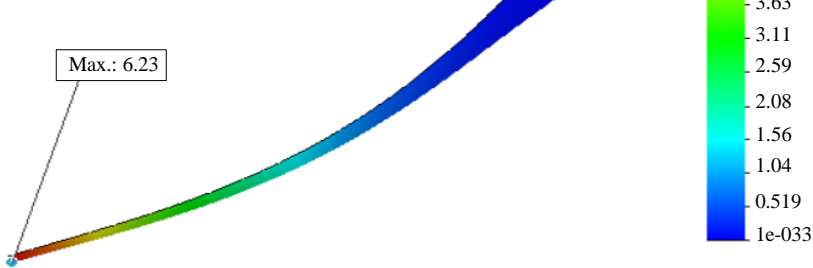

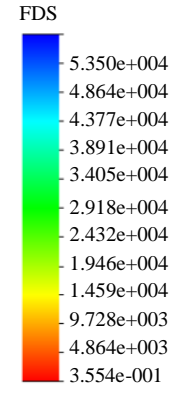

Fig. 9: a) Distribution of static tensions as von Mises criterion; b) Distribution of large displacements and c) Distribution safety factor regarding the elastic limit of the material
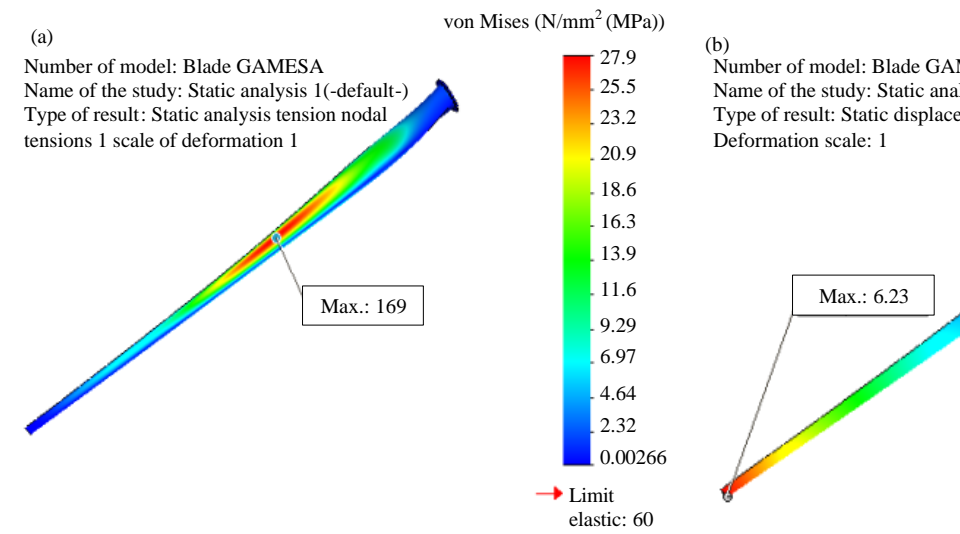

URES (m) Type of result: Safety factor Safety factor 1 Distribution of security factor: FDS $\min =0.36$

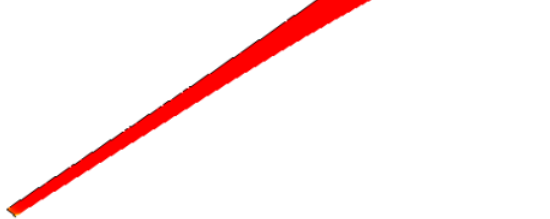

: Bade GAMESA

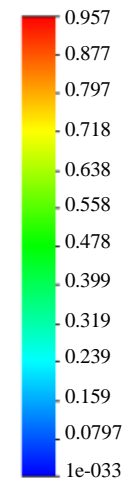

(c)

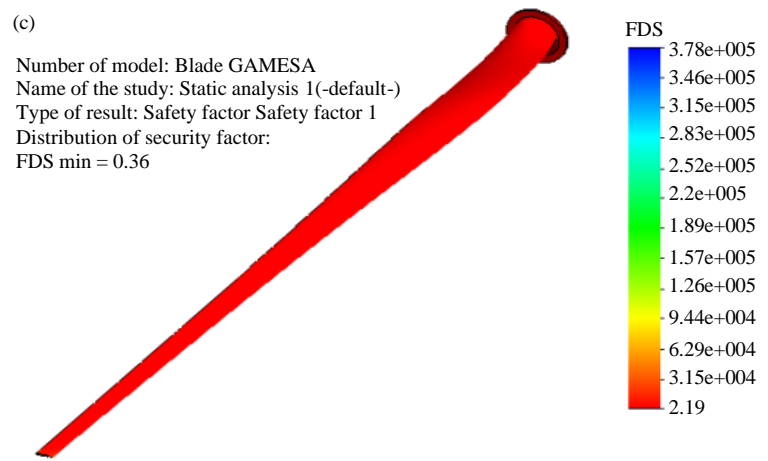

Fig. 10: a) Static stress distribution according to von Mises criterion; b) Distribution of large displacements and c) Distribution safety factor regarding the elastic limit of the material 
Table 2: von Mises stresses, displacements and safety factors as the blade position $0^{\circ}$

\begin{tabular}{lccc}
\hline $0^{\circ}$ & $\begin{array}{c}\text { Maximum } \\
\text { stresses (MPa) }\end{array}$ & $\begin{array}{c}\text { Displacements } \\
(\mathrm{M})\end{array}$ & $\begin{array}{c}\text { Coefficient } \\
\text { of security }\end{array}$ \\
\hline $118 \mathrm{~km} / \mathrm{h}, 98000 \mathrm{~Pa}$ & 44.2 & 1.64 & 1.40 \\
$154 \mathrm{~km} / \mathrm{h}, 97900 \mathrm{~Pa}$ & 73.7 & 2.73 & 0.81 \\
$178 \mathrm{~km} / \mathrm{h}, 96400 \mathrm{~Pa}$ & 96.1 & 3.56 & 0.62 \\
$210 \mathrm{~km} / \mathrm{h}, 94400 \mathrm{~Pa}$ & 129.0 & 4.76 & 0.47 \\
$250 \mathrm{~km} / \mathrm{h}, 92000 \mathrm{~Pa}$ & 169.0 & 6.23 & 0.36 \\
\hline
\end{tabular}

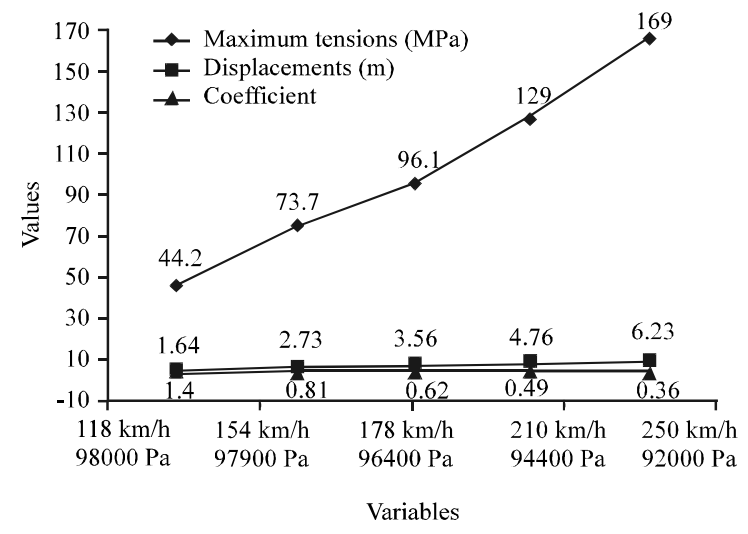

Fig. 11: Graphical representation of the values obtained for the blade to a position of $90^{\circ}$ with respect to the mast

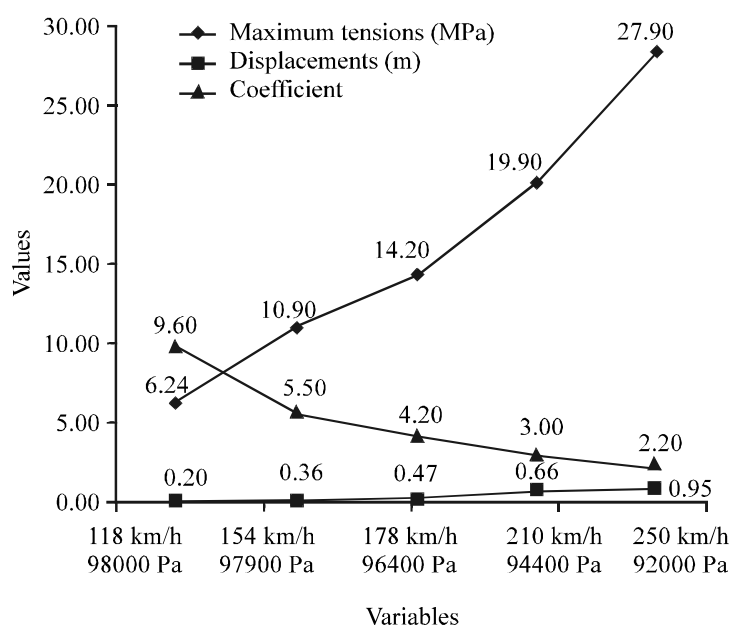

Fig. 12: Graphical representation of the values obtained for the blade to a position of $90^{\circ}$ with respect to the mast

As show in Fig. 11, values stresses and displacements increase as extreme wind speed increases, reaching a peak voltage of $169 \mathrm{MPa}$ and a displacement of $6 \mathrm{~m}$. In addition, the safety factor decreases significantly with a value of 0.36 below the allowable $>1$, validating that in this case the blade can not withstand.

In Fig. 12, it is evident that the values of stresses and displacements increase as the tip speed wind increases
Table 3: von Mises stresses, displacements and safety factors as the position of the blade $90^{\circ}$

\begin{tabular}{lccc}
\hline Position $90^{\circ}$ & $\begin{array}{c}\text { Maximum } \\
(\mathrm{MPa}) \text { stresses }\end{array}$ & $\begin{array}{c}\text { Displacements } \\
(\mathrm{M})\end{array}$ & $\begin{array}{c}\text { Coefficient } \\
\text { of security }\end{array}$ \\
\hline $118 \mathrm{~km} / \mathrm{h}, 98000 \mathrm{~Pa}$ & 6.24 & 0.20 & 9.6 \\
$154 \mathrm{~km} / \mathrm{h}, 97900 \mathrm{~Pa}$ & 10.90 & 0.36 & 5.5 \\
$178 \mathrm{~km} / \mathrm{h}, 96400 \mathrm{~Pa}$ & 14.20 & 0.47 & 4.2 \\
$210 \mathrm{~km} / \mathrm{h}, 94400 \mathrm{~Pa}$ & 19.90 & 0.66 & 3.0 \\
$250 \mathrm{~km} / \mathrm{h}, 92000 \mathrm{~Pa}$ & 27.90 & 0.95 & 2.2 \\
\hline
\end{tabular}

but are lower due to the position that takes the shovel with respect to the wind, reaching a peak voltage of 5.27 MPa and displacements $0.9 \mathrm{~m}$, the safety factor with a value of 2.2 is maintained in the range $>1$ admitted, validating that in this case the blade resists.

\section{CONCLUSION}

The method proposed to determine the mechanical behavior of the blade in the turbine GAMESA G52/850 during the action of extreme wind in validation shows that winds of $250 \mathrm{~km} / \mathrm{h}$ for a $90^{\circ}$ position (Flag) blade withstands the stresses to which it is subjected. In the angle $0^{\circ}$ simulation shows that the blade can not withstand. For winds $>250 \mathrm{~km} / \mathrm{h}$ in either case the blades support these loads. Considering the enormous dimensions of this type of wind turbine and to adverse weather conditions. It not anticipated the possibility of fold down or disassembly is scientifically proved that the "Flag" position is the available option to reduce damage.

\section{ACKNOWLEDGEMENTS}

Experimental Working Group Gibara Wind Farm, the Center for Research and Development (CEDEMA) Agricultural Machinery and the Center for CAD/CAM study of the University of Holguin.

\section{REFERENCES}

Avila-Prats, D., R. Alesanco-Garcia and F. Garcia-Garcia, 2010. [Cost of wind $\mathrm{kWh}$ generated in Cuba, based on wind data from a region with good wind potentials (In Spenish)]. Mech. Eng., 13: 38-45.

Bououden, S., S. Filali and M. Chadli, 2013. Fuzzy predictive control of a variable speed wind turbine. Energy Procedia, 42: 357-366.

Diaz, M.A.R.B., O.A.J. Salgado and F.M. Sosa, 2005. [First document of the eoloelectric project of the wind corridor of the isthmus of tehuantepec]. Institute of Electrical and Electronics, Piscataway, New Jersey. (In Spanish). 
Fernandez-Baqueiro, L.E., J.L. Varela-Rivera and E.J. Felix-Solis, 2009. [Development and calibration of a model for the determination of the field of speeds of hurricane winds in the yucatan peninsula (In Spanish)]. Eng. Res. Technol., 10: 29-37.

Funes Ruiz, J.F., 2009. [Simplified analysis of the structural response of a wind turbine blade]. Master Thesis, Department of Mechanics of Continuous Media and Theory of Structures, Universidad Carlos III Madrid, Getafe, Spain. (In Spanish)

Gebhardt, C., S. Preidikman, J. Massa and G. Weber, 2008. [Aerodynamic and aeroelastic behavior of rotors of horizontal and high power wind generators (In Spanish)]. Comput. Mech., 27: 519-539.

Herrera-Sanchez, O., W. Schellong and V. Gonzalez-Fernandez, 2010. [Model of analysis of maximum loads in wind turbines produced by extreme winds (In Spanish)]. Mech. Eng., 13: 22-31.

Kaimal, J.C., J.C.J. Wyngaard, Y. Izumi and O.R. Cote, 1972. Spectral characteristics of surface-layer turbulence. Q. J. Royal Meteorol. Soc., 98: 563-589.

Lassig, J.L., C. Palese and A. Apcarian, 2011. [Extreme winds in the province of Neuquen (In Spanish)]. Meteorol., 36: 83-93.

Li, H. and Z. Chen, 2008. Overview of different wind generator systems and their comparisons. IET Renew. Power Gener., 2: 123-138.
Limas Rodriguez, P.E., 2013. Dynamic analysis to the support of the high frequency set of the caracas metro. Msc Thesis, Center of CAD/CAM Studies, University of Holguin, Holguin, Cuba.

Limas Rodriguez, P.E., C.A. Trinchet Varela and L. Cuevas Rodriguezyotros, 2017. Model for estimating the power of wind turbines. Proceedings of the 7 th International Symposium on Electrical and Mechanical Engineering for Sustainable Development, June 6, 2017, University of Camaguey, Camaguey, Cuba, pp: 1-9 (In Spanish).

Lizano, O.G., 2007. [Climatology of the wind and waves off the coast of Costa Rica (In Spanish)]. Sci. Technol., 25: 43-56.

Muljadi, E., C.P. Butterfield, B. Parsons and A. Ellis, 2007. Effect of variable speed wind turbine generator on stability of a weak grid. IEEE. Trans. Energy Convers., 22: 29-36.

Preidikman, S. and Y.D. Mook, 2005. Modeling of Linear and Non-Linear Aeroelastic Phenomena: Aerodynamic and Structural Models. In: Modeling Applied to Engineering, Jacovkis, W.P. and R. Armentano (Eds.). National Technological University, Singapore, Asia, pp: 365-388 (In Spanish) 